OPEN ACCESS

Edited by: Erica Giarratano, CONICET Center for the Study of Marine Systems (CESIMAR),

Argentina

Reviewed by:

Ana I. Catarino,

Flanders Marine Institute, Belgium Arindam Sarkar

Bidhan Chandra Krishi

Viswavidyalaya, India

*Correspondence:

Simone Franceschini simone.franceschini@uniroma2.it

†These authors have contributed equally to this work

Specialty section This article was submitted to Marine Pollution, a section of the journa Frontiers in Marine Science

Received: 18 March 2021 Accepted: 28 May 2021

Published: 01 July 2021

Citation

Franceschini S, Cau A, D'Andrea L, Follesa MC and Russo T (2021) Eating Near the Dump: Identification of Nearby Plastic

Hotspot as a Proxy for Potential Microplastic Contamination in the Norwegian Lobster (Nephrops norvegicus)

Front. Mar. Sci. 8:682616. doi: 10.3389/fmars.2021.682616

\section{Eating Near the Dump: Identification of Nearby Plastic Hotspot as a Proxy for Potential Microplastic Contamination in the Norwegian Lobster (Nephrops norvegicus)}

\author{
Simone Franceschini ${ }^{1,2 * t}$, Alessandro Cau ${ }^{2,3+}$, Lorenzo D'Andrea ${ }^{1,2}$, \\ Maria Cristina Follesa ${ }^{2,3}$ and Tommaso Russo ${ }^{1,2}$ \\ ' Laboratory of Experimental Ecology and Aquaculture, Department of Biology, University of Rome Tor Vergata, Rome, Italy, \\ ${ }^{2}$ Consorzio Nazionale Interuniversitario Per Le Scienze Del Mare, Rome, Italy, ${ }^{3}$ Dipartimento di Scienze della Vita e \\ dell'Ambiente, Università degli Studi di Cagliari, Cagliari, Italy
}

Plastic waste dumped in the marine environment has severe ecological, social and economic impacts. In recent years, a series of scientific studies documented the contamination by macroplastic and its impact on marine organisms through the accidental ingestion of microplastics, which also originate from the degradation of macroplastic. However, the relationship between the spatial distribution of marine litter and the ingestion of plastics by organisms have never been related. In this work, we aimed to investigate, through a modeling approach, the relations between potential sources of microplastic particles (i.e., seafloor macroplastic accumulation hotspots detected by means of trawl surveys), and the ingestion by the benthic crustacean Norwegian lobster (Nephrops norvegicus). According to the literature, N. norvegicus is characterized by a sedentary behavior and therefore it has been highlighted as a proficient sentinel species for local microplastic contamination. Despite no significant relation has been found between microplastic ingestion and the local presence of seafloor macroplastic, it seems that proximity to hotspots of macroplastic accumulation is significantly related to microplastics ingestion. These results highlight important considerations on the fate of plastic in the marine environments with significant impacts on biota and the quality of the product caught at sea.

Keywords: pollution, Mediterranean Sea, biondicator, modeling, MEDITS, marine litter

\section{INTRODUCTION}

Every year, large quantities of waste enter the ocean, with plastic alone accounting for ca. 8 million tons of the total material (Jambeck et al., 2015). It is known that plastic objects voluntarily or accidentally dumped into the seas can float or sink and settle on the seabed (GESAMP, 2019). There, due to its persistency in the environment, plastic has become a dominant and widespread element of seafloor litter (Moore, 2008; Thompson et al., 2009), capable to reach secluded environments such as the poles or the deepest regions of the oceans (Bergmann and Klages, 2012; Cau et al., 2018; 
Chiba et al., 2018). When dealing with plastic wastes, size and chemical composition are two key aspects; indeed according to JRC (2013) and GESAMP (2019), macroplastics (MaP hereafter) range between 25 and 1,000 $\mathrm{mm}$, mesoplastics range between 5 and $25 \mathrm{~mm}$, and microplastics (MiP hereafter) are smaller than $5 \mathrm{~mm}$. Size range of $\mathrm{MaP}$ often comprises mesoplastics (e.g., Koelmans et al., 2017), so that MaP are defined as particles $>5 \mathrm{~mm}$ and MiP represent the portion below $5 \mathrm{~mm}$. Size of plastic litter items is a crucial measure in marine litter monitoring (GESAMP, 2019), even because particles' size can affects the potential interaction with biota. However, MaP undergoes environmental and mechanical deterioration/fragmentation into MiP (Frias and Nash, 2019), these last ones have been accumulating in oceans worldwide over the last decades (Avio et al., 2017) and scientific studies have documented how accidental ingestion of MiP by marine organisms occurs (Wright et al., 2013). Due to their small size, MiP are potentially available for ingestion to a wide range of marine species (Jâms et al., 2020), including cetaceans (Lusher et al., 2018), seabirds (Amélineau et al., 2016), mollusks (Ward et al., 2019), echinoderms (Graham and Thompson, 2009), zooplankton (Cole et al., 2013; Desforges et al., 2015), and corals (Hall et al., 2015). Ingested MiP may accumulate within organisms, causing blockages and internal abrasions or be fragmented through the digestion process (Cau et al., 2020). In addition, plastic particles may have toxic impacts due to monomers and plastic additives that do affect endocrine functions (Oehlmann et al., 2009; Talsness et al., 2009), reduce feeding behavior (Cole and Galloway, 2015), and compromise growth and reproduction (Lee et al., 2013; Lo and Chan, 2018).

Data quantifying MiP contamination in the deep sea are still limited; however, there is evidence of MiP contamination in all matrixes: water (Ferreira et al., 2020), biomass (Courtene-Jones et al., 2017), and sediments (Van Cauwenberghe et al., 2013; Kane and Clare, 2019). The latter matrix showed the highest concentrations of MP ever reported (Bergmann et al., 2017), thereby confirming the hypothesis that seafloor represents the final sink for plastic litter and MiP (Woodall et al., 2014).

In the Mediterranean Sea, all the categories (organic, metal, glass, etc.) of seafloor litter (including plastics) is extensively assessed by means of trawl-survey (Melli et al., 2016; Alvito et al., 2018) while ROV surveys provide detailed observation in habitats not suited for trawling activities (Angiolillo et al., 2015; Cau et al., 2017). Furthermore, predictive models able to estimate marine seabed plastic have been developed in the last decade: recent works focused on the application of machine learning methods to estimate plastic quantities on the seabed (Franceschini et al., 2019) while applications of Lagrangian methods have taken into account ocean circulation and main currents in order to model marine litter transport and fate (Liubartseva et al., 2018). These models and methods are useful since an important part of MiP in marine environments can be generated via fragmentation of larger plastic items (secondary microplastics), which persist in the environment for a long time (Barnes et al., 2009). Although fragmentation rates are largely unknown (Koelmans et al., 2017), it seems reasonable that the portion of $\mathrm{MiP}$ that does not reach directly the marine environment but originates from $\mathrm{MaP}$ weathering, embrittlement, and fragmentation (Andrady, 2017) depends upon the amount of $\mathrm{MaP}$ and the redistribution determined by environmental factors such as water currents. In effect, different studies emphasized how concentration of MiP tends to be higher in those areas where MaP accumulates (Wright et al., 2013; Shim and Thomposon, 2015). Even if the portion of MiP originated from MaP are likely to be smaller when compared to terrestrial sources, recent works have highlighted how trawling activities significantly affect local quantities of plastic debris, acting both as input and as fragmentation and redistribution agents of the seafloor plastic litter (Franceschini et al., 2019). Therefore, the possible availability of MiP to marine organisms dwelling in proximity of these areas increases beside the abundance of seafloor MaP, and the spatial relationship between seafloor hotspots of $\mathrm{MaP}$ and incidence of microplastics ingestion should be investigated using appropriate statistical approaches.

In summary, we know one of the sources of MiP, that is the marine litter (that is $\mathrm{MaP}$ ), and we also know that MiP enter into the trophic nets, whereas the quantitative dynamics connecting these two aspects are still largely unknown and challenging from a modeling point of view. In this scenario, even if several studies allowed to assess macroplastic densities and MiP ingestion by benthic organisms, the relation between the accumulation of plastic items in the seabed/seafloor and organisms ingestion rates has not been established yet. This relation is potentially relevant to model and predict the consequences of spatial MaP accumulation on demersal organisms (including species of high value for fisheries). In fact, existing data about seafloor MaP have only recently been linked to the occurrence of MiP in benthic organisms that feed in those areas. For example, Alomar et al. (2020) conducted a study in western Mediterranean Sea, relating $\mathrm{MiP}$ ingestion in demersal species caught by trawls and the amount of seafloor plastics caught in the same haul. In last decades, it has been also proved how a consistent part of $\mathrm{MaP}$ debris originates from maritime activities including shipping and fishing (Barnes et al., 2009; Browne, 2015; Galgani, 2015).

In recent years, Cau et al. (2019) focused on the use of the Norwegian lobster Nephrops norvegicus (Linnaeus, 1758) as flagship species to investigate the fate of $\mathrm{MiP}$ in deepsea environments and their availability to benthic biota. This decapod crustacean has relevant ecological roles in the trophic food webs of deep Mediterranean Sea, and it is among the most valuable fisheries resource in European Atlantic and Mediterranean waters, with landings worth cumulatively hundreds of millions of Euros (Ungfors et al., 2013; Sbrana et al., 2019).

In view of this, in order to evaluate sensitive zones of MiP availability to marine fauna, different environmental and anthropic factors should be considered, so as to properly assess the relation between plastic accumulated on the seafloor and the fraction of it that can ultimately become a source of MiP to benthic and demersal fauna.

In this work, we merged information on $\mathrm{MiP}$ present in $N$. norvegicus stomach contents, seafloor $\mathrm{MaP}$ accumulation hotspots and data on fishing effort of the Italian fleet, in order to test for possible relations among these factors. This paper therefore aims to model these relationships with the view of a better understanding of the potential sources which lead to 
a greater occurrence of $\mathrm{MiP}$ in the stomach of the Norwegian lobster and benthic fauna. In investigating the link between the amount of MaP in the seabed floor and the amount of MiP ingested by invertebrates we are aware to skip a step (the whole reconstruction of the origin and distribution of MiP, which is beyond the scope of this paper), but we argue that the potential existence of this link, if any, could provide insights about the environmental effects of marine litter and indicate new perspectives for researches in this field.

\section{MATERIALS AND METHODS}

\section{Study Area and Data Collection}

The area of research encompasses the Geographic Sub Areas (GSA hereafter ${ }^{1}$ ) 11.1 (Western Sardinia) and 11.2 (Eastern Sardinia), and comprises all waters around the island of Sardinia, Italy. Data on seafloor macroplastic litter were collected in the framework of the MEDiterranean International Trawl Survey (MEDITS) campaign (Bertrand et al., 2002), which is based on a stratified random design with a number of hauls that is proportional to bathymetric strata extension (i.e., 10-50, 51$100,101-200,201-500$, and 501-800 m). A total of 111 hauls were carried out in 2017 and 2018 (Figure 1) and all litter items collected in the catches were classified according to the categories proposed by Fiorentino et al. (2013) and listed in the MEDITS protocol (Bertrand et al., 2002). Total number of items was computed for each category and, for the purpose of this work, we only considered information related to the "plastic" category (i.e., L1 category according to the MEDITS nomenclature).

The dataset on MiP ingestion in $N$. norvegicus was retrieved from two recent studies on the topic, conducted in the area under scrutiny in the present study (Cau et al., 2020, 2019). Samples used in these studies were collected in the framework of the same MEDITS campaigns, at depths between ca. 270 and ca. $660 \mathrm{~m}$. In brief, a total of 116 samples were collected from 10 sites in 2017 and three sites in 2018 (Figure 1), with a total of 116 stomachs extracted (Table 1). Ranges of biometric data (and sex ratio) of analyzed specimens were Carapace Length (CL) 19.4-54 mm for 71 males and 45 females (see Supplementary Material). A power analysis was performed to confirm that the number of samples assessed ( $n=116$ ) was sufficient to justify the conclusions of the present work (two-tail test, $\alpha=0.01$, power 0.98 ).

\section{Microplastic Extraction and Characterization}

Onboard, specimens were collected and transported in the laboratory for dissection to avoid the risk of contamination from sampling activities. Each stomach was dissected and stored at $-20^{\circ}$ until analysis, for which they were dried at $60^{\circ} \mathrm{C}$ for $24 \mathrm{~h}$ and pottered before extraction. MiP are extracted from dried tissues through a density separation (in $\mathrm{NaCl}$ saturated solution, density 1.2 gram $\left.\mathrm{cm}^{-3}\right)$, followed by filtration on cellulose nitrate membranes ( $8 \mu \mathrm{m}$ pore size), partial digestion in diluted hydrogen peroxide (15\%) and visual sorted for

${ }^{1}$ http://www.fao.org/gfcm/data/maps/gsas/en/
$\mu$-FTIR characterization. The method has been validated and standardized with MiP of different types and sizes, across several environmental matrices, including biota and crustaceans such as N. norvegicus (Avio et al., 2015).

Quality Assurance and Quality Control measures included airborne contamination and procedural controls. The latter consists of $10 \mathrm{~mL}$ of pre-filtered hypersaline solution that undertook all the drying, extraction, digestion and sorting steps of samples. One airborne contamination and procedural control was used per each batch of samples processed and all working solutions were pre-filtered through a nitrate acetate membrane with pore size of $0.45 \mu \mathrm{m}$. Glass and metal materials were used and rinsed with pre-filtered milli-Q water before use. After rinsing, all containers were covered with aluminum foils, which were also kept during digestion, stirring, decantation and filtration steps. After filtration, membranes were kept in glass petri dishes, previously rinsed with pre-filtered milli-Q water. Cotton lab coats were used at all times, and special attention was paid to limit the wearing of synthetic clothes. $\mathrm{NaCl}$ saturated solution was prepared in distilled and pre-filtered $(0.45 \mu \mathrm{m}$ pore size) water.

All particles retrieved on membranes were sorted under a stereo-microscope (x64), photographed, categorized according to shape (fragments; film; pellet/beads; filaments) and measured (maximum length, in $\mathrm{mm}$ ) through the CPCe software (Kohler and Gill, 2006). The average size of particles was estimated per each individual. All extracted particles were characterized using a $\mu$ FT-IR microscope (Spotlight i200, Perkin Elmer) coupled to a spectrometer (Spectrum Two, Perkin Elmer), while the measurements were made using the $\mu$ ATR mode. Following back-ground scans, 32 scans were performed for each particle, with a resolution of $4 \mathrm{~cm}^{-1}$. Spectrum 10 software was used for the output spectra and the identification of polymers was performed by comparison with libraries of standard spectra. Polymers matching for more than $70 \%$ with the reference spectra were validated, while polymers with a match between 60 and $70 \%$ underwent a critical interpretation of the spectra.

Despite the above-described precautions, it was not possible to fully avoid airborne contamination and some textile fibers were found in the control membranes: the $\mu$-FTIR characterization revealed these fibers as non-synthetic and almost constituted of cotton and wool. For this reason, they were not included in the presented results.

\section{Data Processing and Statistical Analysis}

In this study, we investigated the relationship between MaP spatial distribution and $\mathrm{MiP}$ ingestion by individuals of $N$. norvegicus. More in detail, we examined the presence of MiP in the gut of individuals of $N$. norvegicus as a function of 1) local macroplastic occurrence (deriving from MEDITS surveys), that is the abundance of MaP in the different fishing grounds, and 2) distance from the MaP litter hotspots. The local occurrence of $\mathrm{MaP}$ was obtained by standardizing the number of MaP items deriving from MEDITS trawl-survey with respect to a grid with square cells of $1 \mathrm{~km}^{2}$ area. Successively, a series of MaP litter hotspots was identified using an Inverse Distance Weighting (IDW) 2D interpolation (Falivene et al., 2007), thereby obtaining 

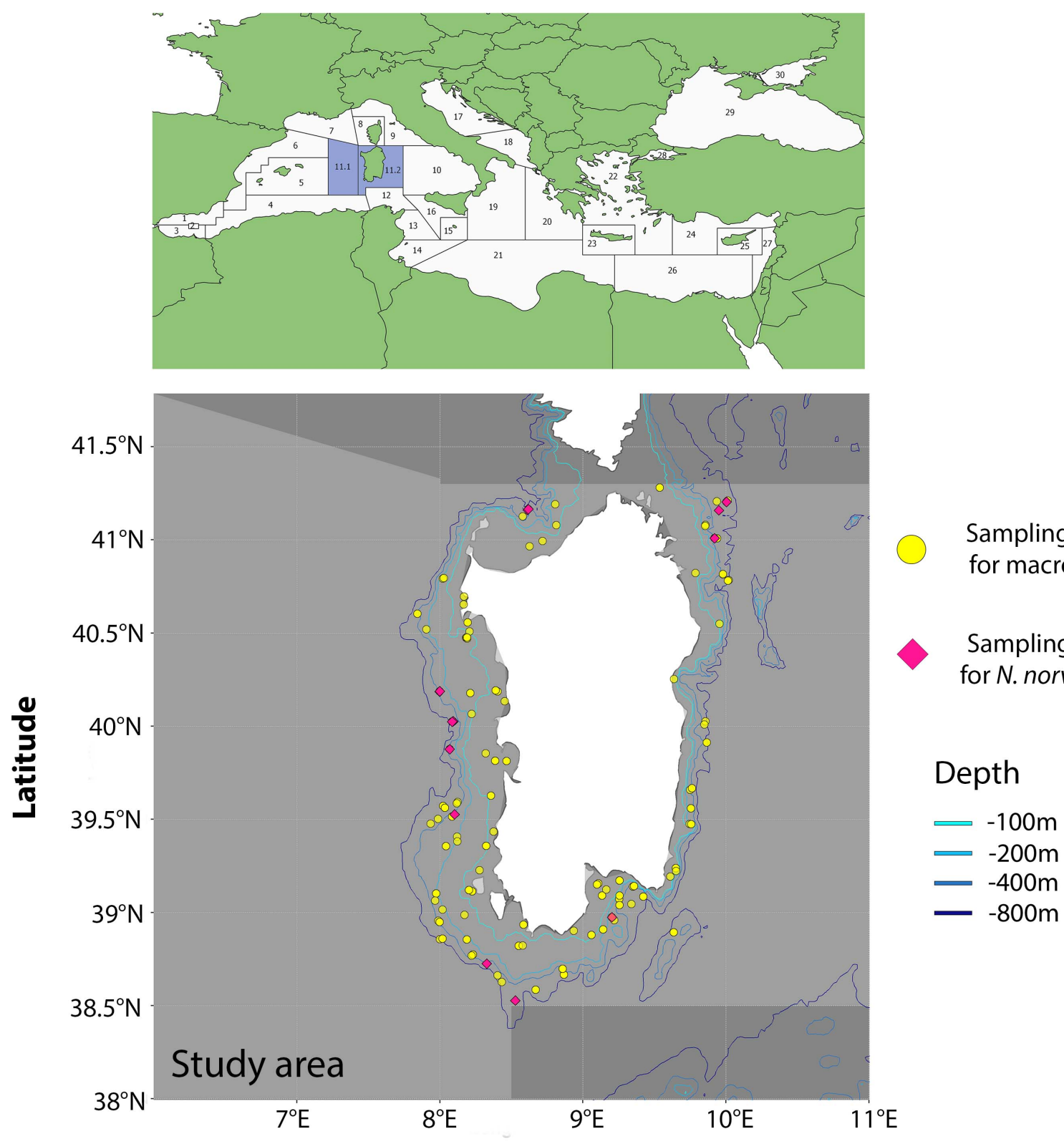

Longitude

FIGURE 1 | Study area with the GSAs 11.1 and 11.2 evidenced (light gray). Purple diamonds refer to sites where samples of N. norvegicus were collected. Yellow points refer to MEDITS sampling sites where plastic items were collected.

an extended map of the potential zones where plastic litter tends to sink and accumulate. Input variables taken into account for interpolation were longitude, latitude and depth while estimation errors were assessed using cross validation techniques (CV). This methodology did not obviously aim at obtaining accurate estimation of the number of plastic items, since its purpose was only to highlight areas where higher amounts of $\mathrm{MaP}$ can be found according to the MEDITS data. In this way, the 90th percentile of the interpolated distribution was computed on the grid of the number of MaP items, so higher values were empirically set to ease the identification of hotspots accumulation areas. The positions of these hotspots were used to compute the distance from them of the spatial origin of $N$. norvegicus specimens (i.e., the fishing ground - MEDITS haul) and investigate its effect on the number of ingested MiP.

In order to exploit fishing effort information as explanatory variable for analysis, fishing activities about the commercial fleet operating in the GSAs 11.1 and 11.2 was reconstructed for the years 2017-2018 by analyzing Vessel Monitoring System (VMS) data with the add-on package VMSbase (Russo et al., 2016, 
TABLE 1 | Sites ID and year of sampling; number of individuals of N. norvegicus collected, geographical coordinates and average depth of trawls.

\begin{tabular}{|c|c|c|c|c|c|}
\hline Site/Year & No. of individuals & Latitude (N) & Longitude (E) & Average depth (m) & References \\
\hline $1 / 2018$ & 10 & $40^{\circ} 30^{\prime} 40^{\prime \prime}$ & $7^{\circ} 54^{\prime} 15^{\prime \prime}$ & 402 & Cau et al., 2020 \\
\hline $2 / 2018$ & 8 & $40^{\circ} 36^{\prime} 07^{\prime \prime}$ & $7^{\circ} 49^{\prime} 58^{\prime \prime}$ & 656 & " \\
\hline $3 / 2018$ & 9 & $41^{\circ} 10^{\prime} 42^{\prime \prime}$ & $8^{\circ} 47^{\prime} 37^{\prime \prime}$ & 415 & “ \\
\hline $1 / 2017$ & 9 & $40^{\circ} 59^{\prime} 75^{\prime \prime}$ & $9^{\circ} 56^{\prime} 09^{\prime \prime}$ & 400 & Cau et al., 2019 \\
\hline $2 / 2017$ & 10 & $41^{\circ} 09^{\prime} 29^{\prime \prime}$ & $9^{\circ} 57^{\prime} 02^{\prime \prime}$ & 535 & “ \\
\hline $3 / 2017$ & 7 & $41^{\circ} 11^{\prime} 98^{\prime \prime}$ & $10^{\circ} 00^{\prime} 16^{\prime \prime}$ & 655 & “ \\
\hline $4 / 2017$ & 10 & $41^{\circ} 09^{\prime} 39^{\prime \prime}$ & $8^{\circ} 36^{\prime} 49^{\prime \prime}$ & 425 & $"$ \\
\hline $5 / 2017$ & 5 & $40^{\circ} 10^{\prime} 68^{\prime \prime}$ & $7^{\circ} 59^{\prime} 55^{\prime \prime}$ & 410 & $"$ \\
\hline $6 / 2017$ & 10 & $40^{\circ} 01^{\prime} 34^{\prime \prime}$ & $8^{\circ} 05^{\prime} 38^{\prime \prime}$ & 630 & “ \\
\hline $7 / 2017$ & 10 & $39^{\circ} 51^{\prime} 93^{\prime \prime}$ & $8^{\circ} 03^{\prime} 66^{\prime \prime}$ & 470 & $"$ \\
\hline $8 / 2017$ & 11 & $39^{\circ} 30^{\prime} 95^{\prime \prime}$ & $8^{\circ} 05^{\prime} 71^{\prime \prime}$ & 380 & “ \\
\hline $9 / 2017$ & 8 & $38^{\circ} 43^{\prime} 30^{\prime \prime}$ & $8^{\circ} 19^{\prime} 39^{\prime \prime}$ & 272 & $"$ \\
\hline $10 / 2017$ & 9 & $38^{\circ} 31^{\prime} 38^{\prime \prime}$ & $8^{\circ} 31^{\prime} 38^{\prime \prime}$ & 604 & “ \\
\hline
\end{tabular}

2014) in the R statistical software environment ( $\mathrm{R}$ Development Core Team, 2019). The time of activity-in hours-of the 312 vessels was estimated and the fishing effort for each vessel was computed in relation to a grid with square cells of $1 \mathrm{~km}^{2}$ area. Only information about bottom otter trawlers was kept for the purpose of analysis since, apart from being the predominant fishing activity in the area, it is the activity that has the greatest impact on the fishing of Norway lobster (Russo et al., 2019) and on the fragmentation of seafloor plastic litter (Franceschini et al., 2019). Moreover, information about individuals lengthmeasured ad Carapace Length (CL) (Farmer, 1974) - and mean size of ingested microplastics were taken into account, since these may have relations with the number of particles present in the stomach of $N$. norvegicus individuals.

An exploratory analysis was conducted to assess relationships between MiP particles in N. norvegicus and fishing effort and $\mathrm{MaP}$ related parameters. To model these patterns, key factors in Table 2 were considered:

In order to use distances from main MaP hotspots, a sum of the distances between the coordinates of $N$. norvegicus hauls and hotspot cells was computed by summing the vectors of Euclidean

TABLE 2 | Input variables taken into account for modeling approach.

\begin{tabular}{llll}
\hline Variable & $\begin{array}{l}\text { Unit of } \\
\text { measurement }\end{array}$ & Time interval & Source \\
\hline Depth & Meters & $2017-2018$ & $\begin{array}{l}\text { marmap functions } \\
\text { (Pante and }\end{array}$ \\
& & $\begin{array}{l}\text { Simon-Bouhet, } \\
\text { 2013) }\end{array}$ \\
$\begin{array}{l}\text { Number of MaP } \\
\text { items }\end{array}$ & N/km² & MEDITS \\
$\begin{array}{l}\text { Distance from main } \\
\text { MaP hotspots }\end{array}$ & $\begin{array}{l}\text { Weighted Euclidean } \\
\text { distance from }\end{array}$ & $2017-2018$ & MEDITS \\
hotspots cells (see & & \\
Fishing effort & below). & & \\
$\begin{array}{l}\text { Horapace length } \\
\text { Mean size of MiP }\end{array}$ & $\begin{array}{l}\text { Millimeters } \\
\text { Mean number }\end{array}$ & $2017-2018$ & VMS data \\
\end{tabular}

distances. Each vector of distance was weighted for the value of the number of MaP items in the hotspot cell.

The multivariate analysis was based on the use of GAMs, a non-parametric extension of GLMs that includes smooth functions (a piecewise polynomial curve) of explanatory variables (Leathwick et al., 2006). In particular, a delta generalized additive modeling GAM approach was applied to account for zeroinflation (also known as Hurdle or Two-stage) (Rubec et al., 2016), since this method is suitable in cases of large proportions of zeros in the observations. In this approach, the positive values were fitted by a GAM using a Gaussian distribution, while the presence-absence data were fitted by a GAM with a binomial distribution. The smoother function used was a penalized cubic regression spline; the procedure automatically selects the degree of smoothing based on the Generalized Cross-Validation (GCV) score. Modeling procedure was applied on log-transformed data.

GAMs were fitted using the $m g c v$ package (Wood, 2012) and the best model was selected using the criteria of explained deviance, the GCV score and the Akaike Information Criterion (AIC) (Akaike, 1973), which provides a balance between model fit and parameters used (Kramer, 2005). All the combinations of employed variables were investigated and selection of best models was evaluated by $m g c v$ functions according to the abovedescribed criteria.

\section{RESULTS}

Through the extraction protocol, a total of ca. 2,400 MiP have been isolated for the confirmation of their polymeric nature through $\mu$-FTIR. In detail for 127 out of 730 (Cau et al., 2020) and 413 out of ca. 1,700 (Cau et al., 2019) the polymeric nature was confirmed, representing a range of $17-24 \%$ of all extracted particles. In all the 13 sites considered for relating MiP ingestion with explanatory variables, there was the presence of at least one organism that was positive to MiP ingestion.

Out of the 116 samples, only 14 did not show the presence of any MiP in their stomach (ca. 12\%). Overall, pooling the dataset of the two studies together, the average number of particles in 


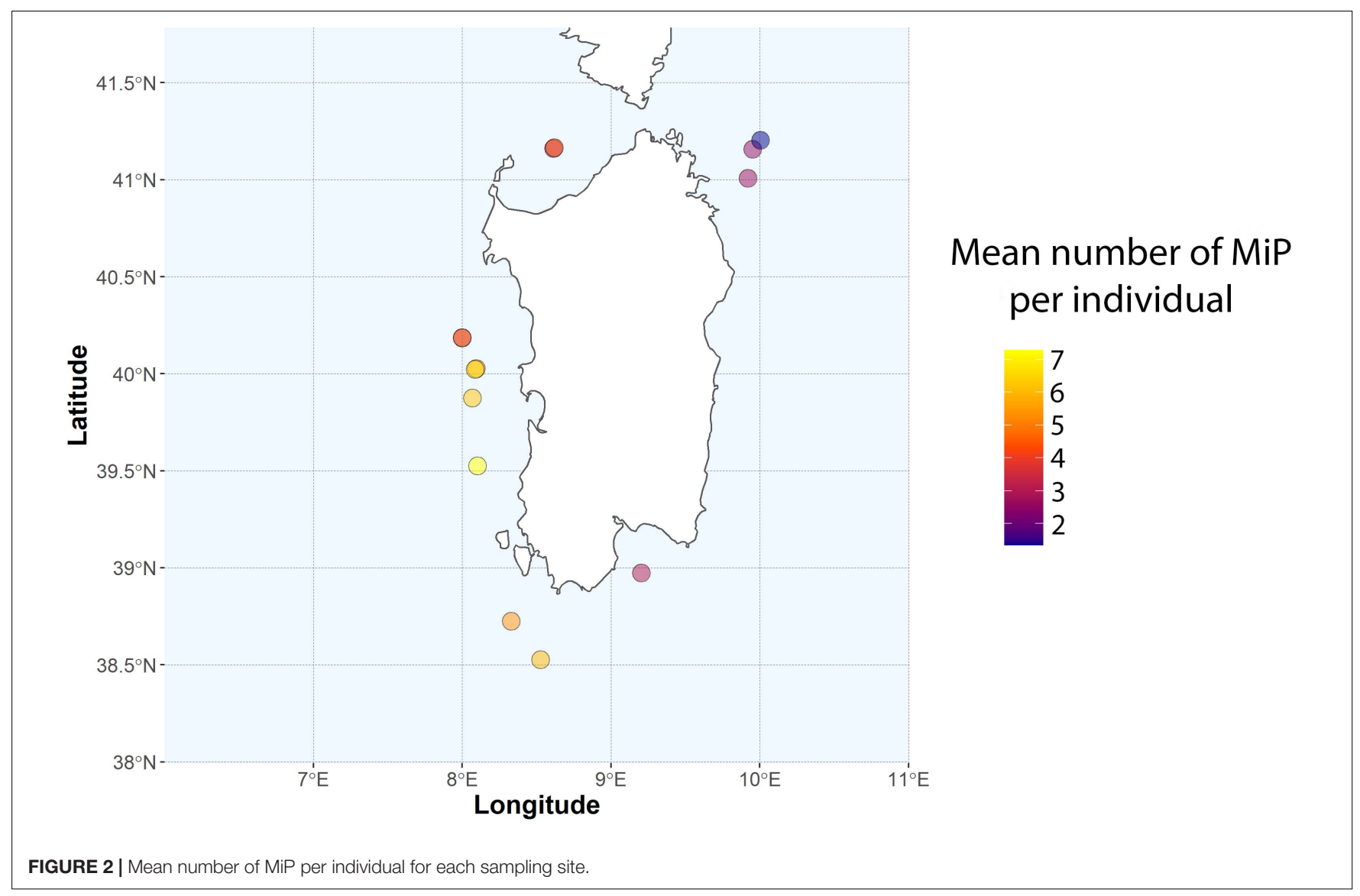

contaminated individuals was $4.75 \pm 0.76$ particles ind $^{-1}$, which was consistent across years: $4.64 \pm 0.73$ and $4.85 \pm 0.76$ particles ind $^{-1}$ in 2017 and 2018, respectively. With respect to the shape of particles, films and fragments were the dominant categories, accounting cumulatively for ca. $76 \%$ and $17 \%$ of the isolated MP, respectively, followed by filaments $(7 \%)$.

The highest mean number of MiP in the stomach was observed in the western and the southern part of Sardinia ( $>40$ particle individual $^{-1}$, in 2017). Mean number of particles per haul range from a minimum of $1.33 \pm 1.75$ to a maximum of $7.27 \pm 12.20$ (Figure 2).

\section{Fishing Effort and Macroplastic Hotspots}

Trawling effort around the Sardinia island is highly variable (Figure 3), with fishing grounds mainly located near the coast in the western side of the island and off-shore in the eastern side. Normalized number of $\mathrm{MaP}$ items from MEDITS data ranged from 9.2 to 506 items $\mathrm{km}^{-2}$ (mean $=83.5 \pm 107.9)$ are shown in Figure 4A. Resulting hotspots ( $>90$ th percentile of the values) of $\mathrm{MaP}$ accumulation (Figure 4B), obtained on the Interpolated log-values of the number of MaP items obtained via IDW (Figure 4A), indicate that, on the basis of MEDITS data, the western and the southern coastal areas of Sardinia correspond to a greater occurrence in terms of number of $\mathrm{MaP}$ items with respect to the other areas.

\section{GAM Model}

The best models (Table 3 ) were selected by $m g c v$ functions taking into account the lowest GCV value, the highest percentage of explained variance and the AIC. The selected GAM models identified statistically significant additive effects of weighted Euclidean distance from the hotspots of macroplastic, depth and fishing effort. Moreover, permutational multivariate analysis of variance using Manhattan distance matrix proved that number of MiP in the gut of $N$. norvegicus and the distance from plastic hotspots are significantly related $(p<0.05)$.

According to the AIC and deviance explained (\%DEV), the Best GAM model was identified as the one including the following variables: depth, weighted distance from main MaP hotspots, fishing effort and mean size of MiP ingested. The smoothing graph (Figure 5) shows how the number of MiP in the gut of $N$. norvegicus increases in the proximity of hotspots of seafloor MaP. Moreover, according to the model, number of MiP ingested by Norwegian lobster showed to have a positive correlation both with fishing effort and depth.

The predicted number of MiP in the gut of $N$. norvegicus for the GSAs 11.1 and 11.2, using the GAM model based on depth and distance from main plastic hotspots (Figure 6), clearly indicates that MiP ingestion occurs mainly in the southern and western coastal areas of Sardinia. Prediction was performed only for the bathymetric range where species are most likely to occur. (i.e., 200-800 m) (Aguzzi et al., 2003). This output was performed 


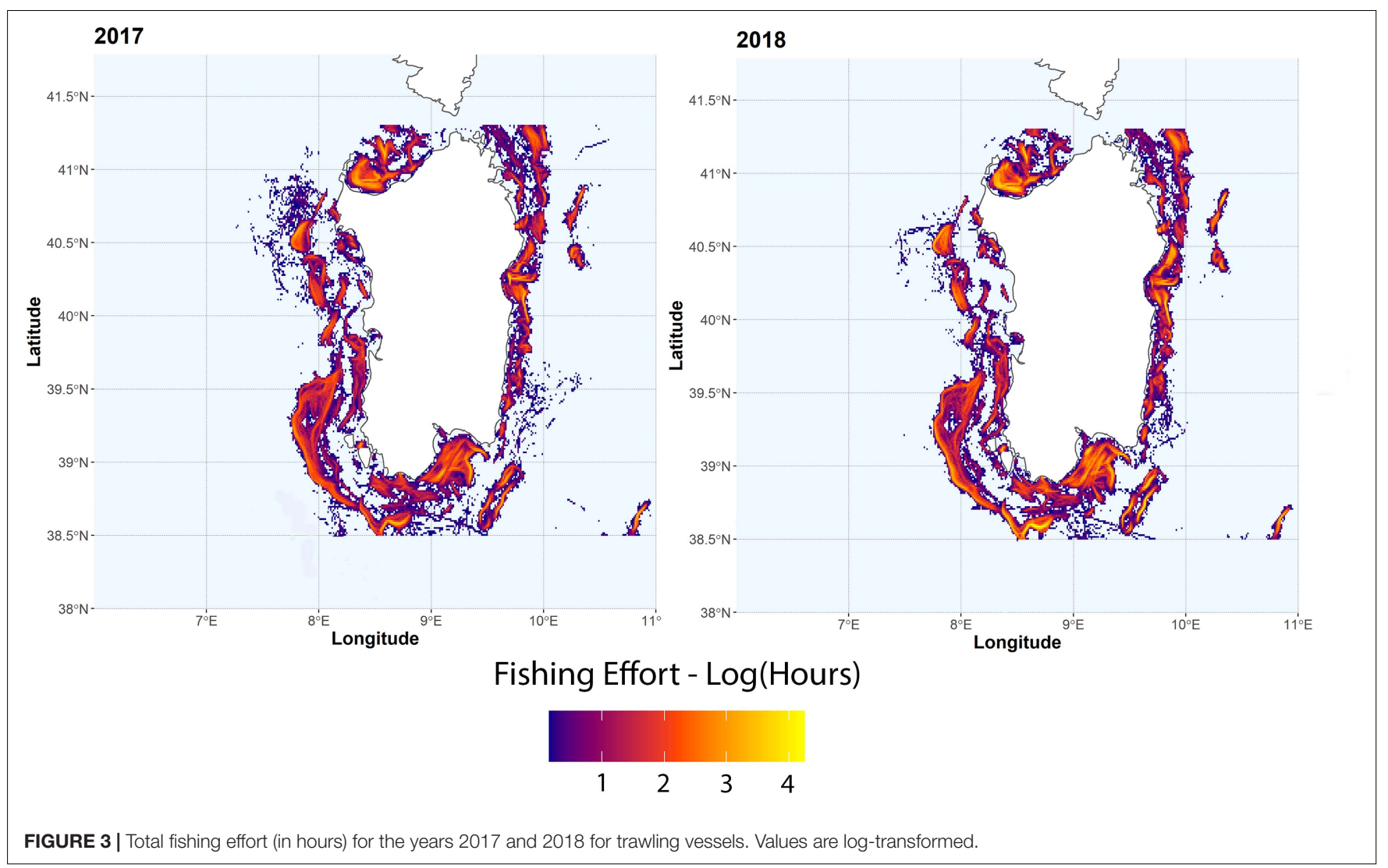

A

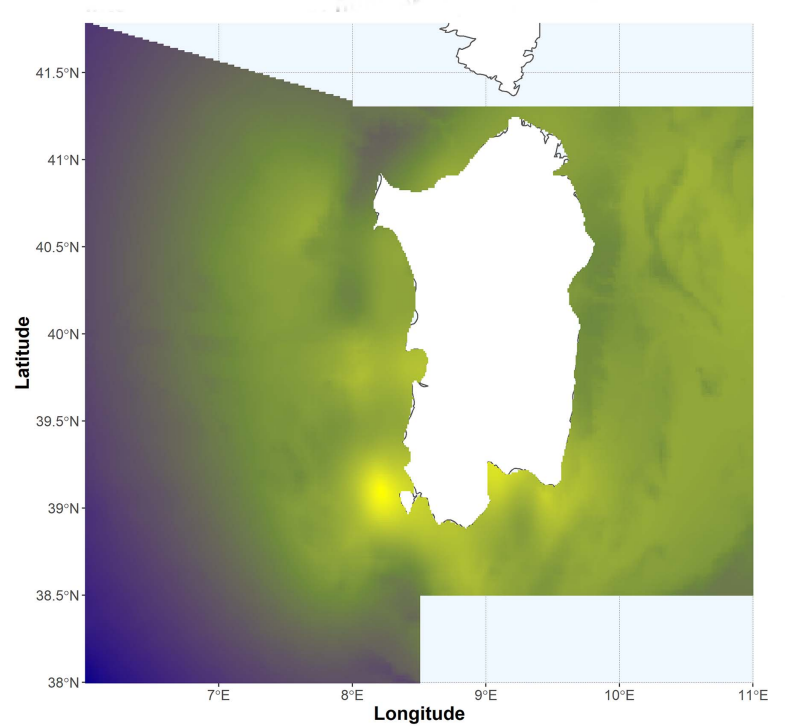

Number of MaP items (Log)

12345
B

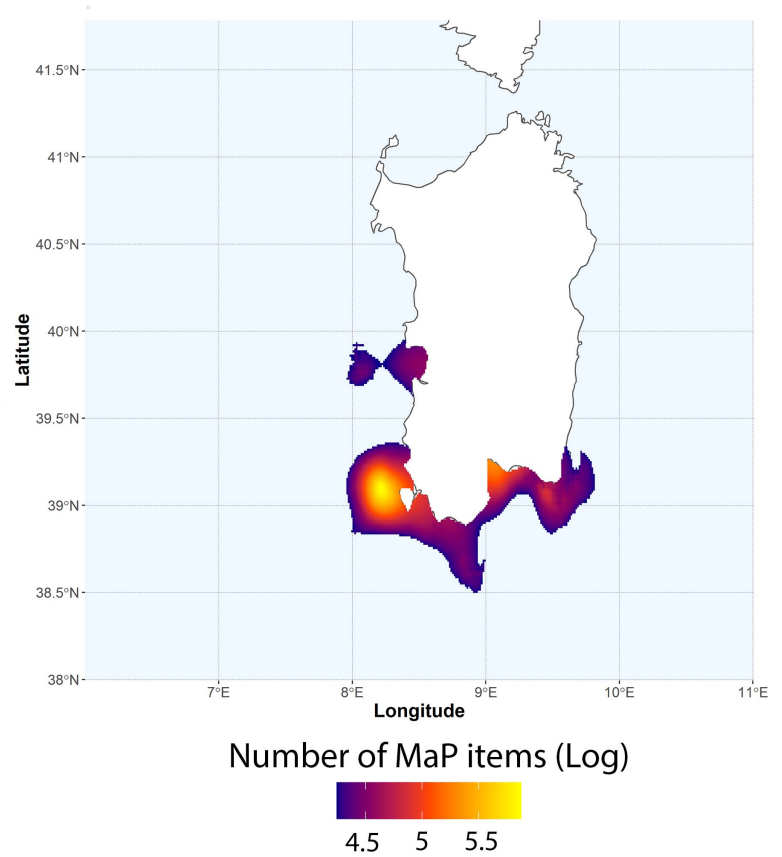

FIGURE 4 | (A) Interpolated log-values of number of plastic items via IDW. (B) Computed hotspots of plastic accumulation according to the 90th percentile. 
TABLE 3 | GAM models ordered according to the AIC lowest value.

\begin{tabular}{|c|c|c|c|c|c|c|c|c|c|}
\hline Depth & dHotspot & Fishing effort & $\mathrm{CL}$ & MiP size & Macroplastic & $\mathrm{AICc}$ & $\%$ Dev & GCV & $\mathbf{R} 2$ \\
\hline \multirow[t]{4}{*}{0.78444} & -0.51112 & 0.272835 & 0.620557 & 1.255397644 & & 85.9093 & 31.3 & 0.1147 & 0.251 \\
\hline & -0.26541 & & 0.599161 & 1.146932656 & & 86.28803 & 23.7 & 0.11897 & 0.195 \\
\hline & -0.36883 & 0.146576 & & 1.192714469 & & 86.55045 & 23.6 & 0.1201 & 0.191 \\
\hline & -0.34395 & 0.159263 & 0.644164 & 1.132760638 & & 86.62283 & 24.1 & 0.11956 & 0.196 \\
\hline 0.8321 & -0.55403 & 0.288475 & & 1.332179446 & 0.008602 & 87.77557 & 31.7 & 0.11623 & 0.248 \\
\hline 0.822506 & -0.53063 & 0.309109 & 0.653429 & 1.275012728 & 0.012365 & 87.84201 & 33.4 & 0.11531 & 0.26 \\
\hline
\end{tabular}

For an easier representation, only the top 10 models were shown.

DHotspot, distance from MaP hotspots; CL, carapace length; MiP size, mean size of MiP per individual; Macroplastic, number of MaP items.
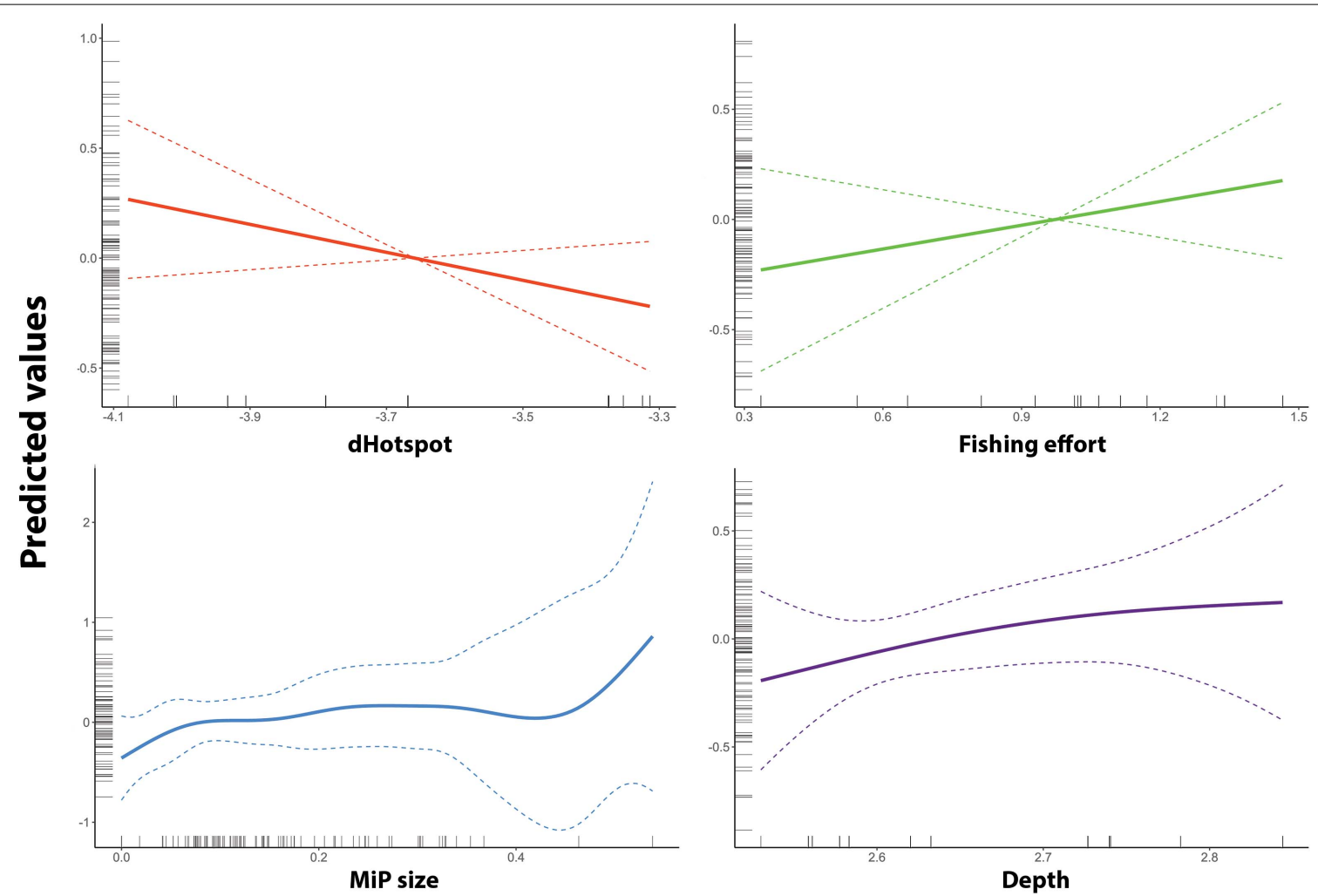

FIGURE $\mathbf{5}$ | Smooth term prediction for each of the four smooth terms used in the GAM of MiP occurrence. Respectively (on x-axis): Depth (blue), fishing effort ("Fishing Effort" - gold), distance from MaP hotspots ("DistHot" - red), number of MaP items ("MaP" - green). Predicted values (on y-axis) are on log-scale. The dotted line represents $95 \%$ confidence interval.

to evidence possible areas where a major number of ingested MiP can be found in N. norvegiucs according to the importance highlighted by the GAM approach.

\section{DISCUSSION}

This study indicates that the number of $\mathrm{MiP}$ ingested by $N$. norvegicus has a significant relationship with the distance from the main hotspots where seafloor MaP accumulates. The number of ingested particles of MiP, indeed, was higher when
Nephrops fishing grounds were closer to accumulation hotspots of $\mathrm{MaP}$, regardless of the presence and abundance of $\mathrm{MaP}$ collected locally, within the same haul. Bearing in mind that the distribution of $\mathrm{MiP}$ and their availability for ingestion are actually unknown, and that other factors such as marine currents and MiP inputs from land could affect MiP distribution, it seems reasonable to speculate about the spatial coherence between $\mathrm{MaP}$ and $\mathrm{MiP}$ ingestion patterns, since a large proportion of MiP originates from MaP. However, "correlation does not imply causation" and therefore it is not possible to deduce a cause-andeffect relationship between distance from $\mathrm{MaP}$ hotspots and $\mathrm{MiP}$ 


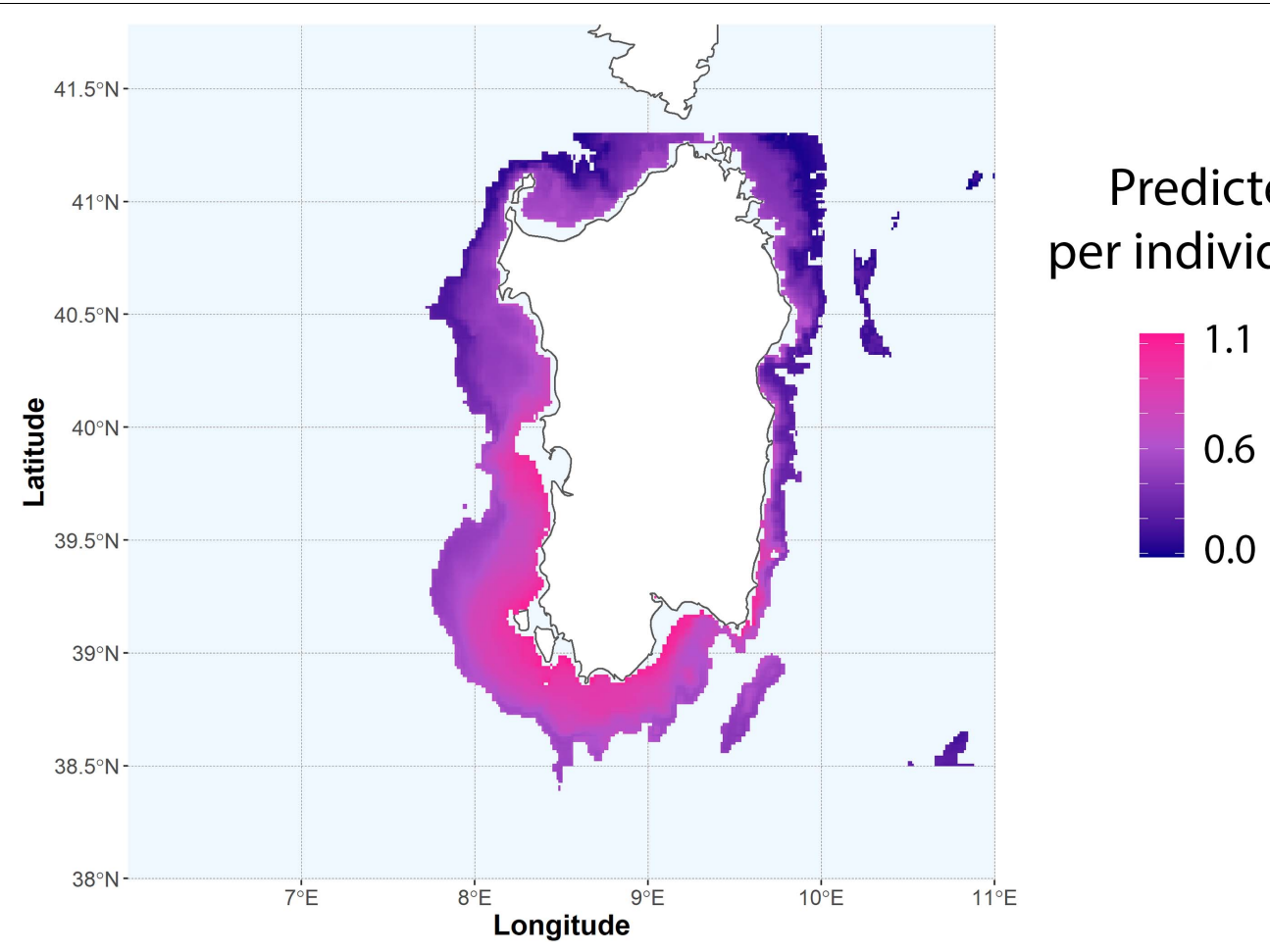

FIGURE 6 | Predicted values of MiP per individual according to the GAM model based on depth and distance from plastic hotspots. Predicted values are on log-scale.

ingestion. Nevertheless, the results of this study deserve further investigations and, given that the assessment of MiP distribution in the marine environment is still in its infancy, it confirms the urgent need to deepen all aspects related to the genesis and distribution of this type of pollutants.

Contrarily to what would have expected, the presence and amount of MaP items in the same hauls where individuals of $N$. norvegicus were collected, did not represent a significant factor to predict the contamination of $N$. norvegicus samples. This result can be explained by the fact that the amount of $\mathrm{MaP}$ items collected in a fishing ground could be misleading due to the continuous trawling activities and annexed displacement of items (Franceschini et al., 2019). Recent works demonstrated that fishing vessels, especially trawling vessels, act as sweepers of the sea, thereby redistributing litter at the boundaries of the main fishing grounds (Buhl-Mortensen and Buhl-Mortensen, 2018; Franceschini et al., 2019). Consequently, the amount of plastic collected in a haul represents only a part of the total plastic that was previously present in a certain site, since a fraction of this could have been dislocated by trawling activities. Our results corroborate this hypothesis since cells where major fishing effort occurs corresponded to those where lower quantities of MaP items were found.

We acknowledge how the whole set of processes that relate seafloor litter accumulation hotspots and the contamination of Norway lobster is complex and multiple factors can be invoked to contribute to the journey of plastic particles: the polymeric nature of plastics items, their fragmentation/degradation time, their mobility and, finally, the feeding behavior of the species that ingests particles. All these factors concur and interrelate to affect the potential number of ingested MiP. We also acknowledge how information about local quantities of $\mathrm{MiP}$ accumulated in sediments represent a relevant input variable for the modeling approach. However, since this information was missing, we focused our investigation on local $\mathrm{MaP}$ and accumulation hotspots so that to test as to whether the quantities of seafloor macroplastic can be a significant indicator of a potentially higher number of contaminated individuals and of ingested particles in nearby areas. Our results showed, indeed, not only that plastic hotspots are important variable that can alter the amount of MiP potentially available to benthic species (La Beur et al., 2019), but also confirms how N. norvegicus represents an efficient bioindicator for MP contamination (Cau et al., 2019; Hara et al., 2020). Indeed, recent studies emphasized how this species faces a considerable accidental ingestion rate, which easily exceeds $80-90 \%$ of positive individuals, regardless of the geographical location. Moreover, despite knowledge on the timing of ingestion and egestion is limited, there is increasing awareness on the fact that this species can experience a retention of larger $\mathrm{MiP}$ in the gut (which can be sometimes bigger than $5 \mathrm{~mm}$; Cau et al., 2019), compared to other anatomical compartments (Martinelli et al., 2021), where they are triturated and egested of smaller dimensions (Cau et al., 2019).

Numerous studies that investigated MiP contamination in benthic organisms reported the absence of a spatial pattern, when comparing the contamination of organisms collected in 
different sites and/or fishing grounds (Murray and Cowie, 2011; Cau et al., 2019, 2020; Hara et al., 2020), rendering MiP contamination practically ubiquitous on the seafloor. Developing solid understanding on the drivers of the distribution of MiP in sediments is essential as we begin to understand their impact on benthic biota and thus sampling strategies are necessarily to be implemented. Our results provide evidence on how seafloor MaP hotspots can be potentially used as predictor for potential contamination in organisms dwelling in their neighboring areas, since MiP films and fragments (the majority of MP particles isolated from our samples of $N$. norvegicus), show an affinity with areas where macroplastic and in general marine litter are common and tend to accumulate (Kane and Clare, 2019). Indeed, recent studies proved how litter accumulation zones can influence the concentrations of MiP in sediments (Browne et al., 2011; Shim and Thomposon, 2015), ultimately emphasizing the importance of using such variable into modeling. Seafloor MaP hotspots could, indeed, become a source of MiP for the effects of mechanical, environmental and even biological fragmentation, which could likely be transported by turbidity currents and deepsea bottom current (i.e., near-bed thermoaline bottom currents), which have been recently identified as major drivers of $\mathrm{MiP}$ distribution in deep-sea environments (Kane and Clare, 2019; Kane et al., 2020).

Although MiP are known to be largely present in the global seafloor, the processes that control their dispersal and concentration in the deep sea remain largely unknown (Kane et al., 2020). Deterministic transport models have faced considerable issues in obtaining accurate estimates of MiP on the seafloor. In fact, they have to take into account complex environmental processes as alterations in vertical migrations defined by size and shape of particles and interactions with biota. In addition, the frequent low resolution of currents and waves data makes it difficult to model the processes which lead to MiP fate and accumulation (Liubartseva et al., 2018), making the use of these variables for this kind of modeling risky and with uncertain results.

Fishing effort and depth variables showed a positive correlation with the number of MiP ingested (Figure 5). This could be related to the activity of trawling vessels which may both represent an important input of macroplastic (Browne, 2015) and increase availability of $\mathrm{MiP}$ to marine organisms through processes of fragmentation and mixing of sediment due to the action of trawl nets (Barnes et al., 2009). As depth, recent studies evidenced how deep sea is a major sink for $\mathrm{MiP}$ debris and accumulation (Van Cauwenberghe et al., 2013; Woodall et al., 2014).

Prediction of MiP based on GAM model based on depth and plastic hotspots clearly showed a high concentration of ingested MiP in the western-southern area of Sardinia (Figure 6). The area where highest values are likely to occur visually correspond to those areas identified as hotspot for $\mathrm{MaP}$. This area includes also important $N$. norvegicus fishing grounds, where the fishing activities targeting this species are most concentrated (Cau et al., 2019; Russo et al., 2019). This does not want to take the role of an accurate predictive model, but it poses an important reflection on the future implications regarding the potential occurrence of MiP in benthic organisms according to plastic hotspots and the quality of the product fished. Moreover, this study lays a foundation stone on what could be the first relationship between the debris present on the seabed and the resulting concentration of $\mathrm{MiP}$ in benthic organisms. Accurately tracing the entire path and fate of MiP from the mainland to final bioaccumulation in marine organisms is a long research process that requires the synergic contribute and effort of different disciplines. This clue, together with others such as those highlighted by Alomar et al. (2020), suggests that there are evident correlations between the bottom areas where plastic tends to accumulate and contamination of $\mathrm{MiP}$ in benthic organisms that live in proximity of these areas.

\section{CONCLUSION}

The use of flagship species as $N$. norvegicus could represent an important step in monitoring and investigating the dynamics of seafloor MiP accumulation and occurrence, especially when information about the quantities of microplastics in the water column or sediment are missing. As anticipated above, our approach did not want to provide a suitable model to predict MiP in the gut of $N$. norvegicus, since many other vertical and horizontal transport mechanisms have proved to influence MiP distribution and, consequently, the availability to benthic fauna (Bergmann et al., 2017; Katija et al., 2017; Kane et al., 2020). However, GAM modeling approach allowed to investigate and highlight which features may (or may not) affect the presence of plastic particles in these organisms. The proximity to $\mathrm{MaP}$ hotspots may thus have a significant effect on the occurrence of MiP also in other deep-sea benthic species with similar feeding behavior. This result suggests evident effects of marine litter accumulation areas on biota and surrounding ecosystems, with strong implications on the trophic chains and, not last, the quality of the product caught at sea.

\section{DATA AVAILABILITY STATEMENT}

The raw data supporting the conclusions of this article will be made available by the authors, without undue reservation.

\section{AUTHOR CONTRIBUTIONS}

SF and AC performed statistical analysis and wrote the manuscript. LD'A analyzed fishing effort data. MF contributed to the experimental design and revised the manuscript. TR supervised the statistical approach and revised the manuscript. All authors contributed to the article and approved the submitted version.

\section{SUPPLEMENTARY MATERIAL}

The Supplementary Material for this article can be found online at: https://www.frontiersin.org/articles/10.3389/fmars.2021. 682616/full\#supplementary-material 


\section{REFERENCES}

Aguzzi, J., Sardà, F., Abelló, P., Company, J. B., and Rotllant, G. (2003). Diel and seasonal patterns of Nephrops norvegicus (Decapoda: Nephropidae) catchability in the western Mediterranean. Mar. Ecol. Prog. Ser. 258, 201-211. doi: 10.3354/ meps 258201

Akaike, H. (1973). Maximum likelihood identification of Gaussian autoregressive moving average models. Biometrika 60, 255-265. doi: 10.1093/biomet/60.2.255

Alomar, C., Deudero, S., Compa, M., and Guijarro, B. (2020). Exploring the relation between plastic ingestion in species and its presence in seafloor bottoms. Mar. Pollut. Bull. 160:111641. doi: 10.1016/j.marpolbul.2020.111641

Alvito, A., Bellodi, A., Cau, A., Moccia, D., Mulas, A., Palmas, F., et al. (2018). Amount and distribution of benthic marine litter along Sardinian fishing grounds (CW Mediterranean Sea). Waste Manag. 75, 131-140. doi: 10.1016/j. wasman.2018.02.026

Amélineau, F., Bonnet, D., Heitz, O., Mortreux, V., Harding, A. M. A., Karnovsky, N., et al. (2016). Microplastic pollution in the Greenland Sea: background levels and selective contamination of planktivorous diving seabirds. Environ. Pollut. 219, 1131-1139. doi: 10.1016/j.envpol.2016.09.017

Andrady, A. L. (2017). The plastic in microplastics: a review. Mar. Pollut. Bull. 119, 12-22. doi: 10.1016/j.marpolbul.2017.01.082

Angiolillo, M., Di Lorenzo, B., Farcomeni, A., Bo, M., Bavestrello, G., Santangelo, G., et al. (2015). Distribution and assessment of marine debris in the deep Tyrrhenian Sea (NW Mediterranean Sea, Italy). Mar. Pollut. Bull. 92, 149-159. doi: 10.1016/j.marpolbul.2014.12.044

Avio, C. G., Gorbi, S., and Regoli, F. (2015). Experimental development of a new protocol for extraction and characterization of microplastics in fish tissues: first observations in commercial species from Adriatic Sea. Mar. Environ. Res. 111, 18-26. doi: 10.1016/j.marenvres.2015.06.014

Avio, C. G., Gorbi, S., and Regoli, F. (2017). Plastics and microplastics in the oceans: from emerging pollutants to emerged threat. Mar. Environ. Res. 128, 2-11. doi: 10.1016/j.marenvres.2016.05.012

Barnes, D. K. A., Galgani, F., Thompson, R. C., and Barlaz, M. (2009). Accumulation and fragmentation of plastic debris in global environments. Philos. Trans. R Soc. Lond. B Biol. Sci. 364, 1985-1998. doi: 10.1098/rstb.2008. 0205

Bergmann, M., and Klages, M. (2012). Increase of litter at the Arctic deep-sea observatory HAUSGARTEN. Mar. Pollut. Bull. 64, 2734-2741. doi: 10.1016/j. marpolbul.2012.09.018

Bergmann, M., Wirzberger, V., Krumpen, T., Lorenz, C., Primpke, S., Tekman, M. B., et al. (2017). High quantities of microplastic in Arctic Deep-Sea sediments from the HAUSGARTEN observatory. Environ. Sci. Technol. 51, 11000-11010. doi: 10.1021/acs.est.7b03331

Bertrand, J. A., de Sola, L. G., Papaconstantinou, C., Relini, G., and Souplet, A. (2002). The general specifications of the MEDITS surveys. Sci. Mar. 66, 9-17. doi: $10.3989 /$ scimar.2002.66s 29

Browne, M. A. (2015). "Global distribution, sources and pathways of microplastics to habitats," in Marine Anthropogenic Litter, eds M. Bergmann, L. Gutow, and M. Klages (Cham: Springer International Publishing), 229-244.

Browne, M. A., Crump, P., Niven, S. J., Teuten, E., Tonkin, A., Galloway, T., et al. (2011). Accumulation of microplastic on shorelines woldwide: sources and sinks. Environ. Sci. Technol. 45, 9175-9179. doi: 10.1021/es20 1811 s

Buhl-Mortensen, P., and Buhl-Mortensen, L. (2018). Impacts of bottom trawling and litter on the seabed in Norwegian waters. Front. Mar. Sci. 5:42. doi: 10.3389/ fmars.2018.00042

Cau, A., Alvito, A., Moccia, D., Canese, S., Pusceddu, A., Cannas, R., et al. (2017). Submarine canyons along the upper Sardinian slope (Central Western Mediterranean) as repositories for derelict fishing gears. Mar. Pollut. Bull. 123, 357-364. doi: 10.1016/j.marpolbul.2017.09.010

Cau, A., Avio, C. G., Dessì, C., Follesa, M. C., Moccia, D., Regoli, F., et al. (2019). Microplastics in the crustaceans Nephrops norvegicus and Aristeus antennatus: flagship species for deep-sea environments? Environ. Pollut. 255:113107. doi: 10.1016/j.envpol.2019.113107

Cau, A., Avio, C. G., Dessì, C., Moccia, D., Pusceddu, A., Regoli, F., et al. (2020). Benthic crustacean digestion can modulate the environmental fate of microplastics in the Deep Sea. Environ. Sci. Technol. 54, 4886-4892. doi: 10. 1021/acs.est.9b07705
Cau, A., Bellodi, A., Moccia, D., Mulas, A., Pesci, P., Cannas, R., et al. (2018). Dumping to the abyss: single-use marine litter invading bathyal plains of the Sardinian margin (Tyrrhenian Sea). Mar. Pollut. Bull. 135, 845-851. doi: 10.1016/j.marpolbul.2018. 08.007

Chiba, S., Saito, H., Fletcher, R., Yogi, T., Kayo, M., Miyagi, S., et al. (2018). Human footprint in the abyss: 30 year records of deep-sea plastic debris. Mar. Policy 96, 204-212. doi: 10.1016/j.marpol.2018.03.022

Cole, M., and Galloway, T. S. (2015). Ingestion of nanoplastics and microplastics by Pacific oyster larvae. Environ. Sci. Technol. 49, 14625-14632. doi: 10.1021/ acs.est.5b04099

Cole, M., Lindeque, P., Fileman, E., Halsband, C., Goodhead, R., Moger, J., et al. (2013). Microplastic ingestion by zooplankton. Environ. Sci. Technol. 47, 6646-6655. doi: 10.1021/es400663f

Courtene-Jones, W., Quinn, B., Gary, S. F., Mogg, A. O. M., and Narayanaswamy, B. E. (2017). Microplastic pollution identified in deep-sea water and ingested by benthic invertebrates in the Rockall Trough, North Atlantic Ocean. Environ. Pollut. 231, 271-280. doi: 10.1016/j.envpol.2017.08.026

Desforges, J.-P. W., Galbraith, M., and Ross, P. S. (2015). Ingestion of microplastics by zooplankton in the Northeast Pacific Ocean. Arch. Environ. Contam. Toxicol. 69, 320-330. doi: 10.1007/s00244-015-0172-5

Falivene, O., Cabrera, L., and Sáez, A. (2007). Optimum and robust 3D facies interpolation strategies in a heterogeneous coal zone (Tertiary As Pontes basin, NW Spain). Int. J. Coal Geol. 71, 185-208. doi: 10.1016/j.coal.2006.08.008

Ferreira, M., ThoMiPon, J., Paris, A., Rohindra, D., and Rico, C. (2020). Presence of microplastics in water, sediments and fish species in an urban coastal environment of Fiji, a Pacific small island developing state. Mar. Pollut. Bull. 153:110991. doi: 10.1016/j.marpolbul.2020.110991

Fiorentino, F., Lefkaditou, E., Jadaud, A., Carbonara, P., Lembo, G., and Galgani, F. (2013). Protocol for litter data collection during the medits trawl surveys. Rapp. Comm. Int. Mer Médit. 40:2013.

Franceschini, S., Mattei, F., D’Andrea, L., Di Nardi, A., Fiorentino, F., Garofalo, G., et al. (2019). Rummaging through the bin: modelling marine litter distribution using artificial neural networks. Mar. Pollut. Bull. 149:110580. doi: 10.1016/j. marpolbul.2019.110580

Frias, J. P. G. L., and Nash, R. (2019). Microplastics: finding a consensus on the definition. Mar. Pollut. Bull. 138, 145-147. doi: 10.1016/j.marpolbul.2018. 11.022

Galgani, F. (2015). Marine litter, future prospects for research. Front. Mar. Sci. 2. doi: $10.3389 /$ fmars.2015.00087

GESAMP, (2019). Guidelines or the Monitoring and Assessment of Plastic Litter and Microplastics in the Ocean. (IMO/FAO/UNESCOIOC/UNIDO/WMO/IAEA/UN/UNEP/UNDP/ISA Joint Group of Experts on the Scientific Aspects of Marine Environmental Protection). Report Studies GESAMP No. 99, eds P. J. Kershaw, A. Turra, and F. Galgani (Madrid: GESAMP), 130.

Graham, E. R., and Thompson, J. T. (2009). Deposit- and suspension-feeding sea cucumbers (Echinodermata) ingest plastic fragments. J. Exp. Mar. Biol. Ecol. 368, 22-29. doi: 10.1016/j.jembe.2008.09.007

Hall, N. M., Berry, K. L. E., Rintoul, L., and Hoogenboom, M. O. (2015). Microplastic ingestion by scleractinian corals. Mar. Biol. 162, 725-732. doi: 10.1007/s00227-015-2619-7

Hara, J., Frias, J., and Nash, R. (2020). Quantification of microplastic ingestion by the decapod crustacean Nephrops norvegicus from Irish waters. Mar. Pollut. Bull. 152:110905. doi: 10.1016/j.marpolbul.2020.110905

Jambeck, J. R., Geyer, R., Wilcox, C., Siegler, T. R., Perryman, M., Andrady, A., et al. (2015). Plastic waste inputs from land into the ocean. Science 347, 768-771. doi: $10.1126 /$ science. 1260352

Jâms, I. B., Windsor, F. M., Poudevigne-Durance, T., Ormerod, S. J., and Durance, I. (2020). Estimating the size distribution of plastics ingested by animals. Nat. Commun. 11:1594. doi: 10.1038/s41467-020-15406-6

JRC, (2013). Guidance on Monitoring of Marine Litter in European Seas. A Guidance Document within the Common Implementation Strategy for the Marine Strategy Framework Directive. MSFD Technical Subgroup on Marine Litter. Ispra: JRC. doi: 10.2788/99475

Kane, I. A., and Clare, M. A. (2019). Dispersion, accumulation, and the ultimate fate of microplastics in deep-marine environments: a review and future directions. Front. Earth Sci. 7:80. doi: 10.3389/feart.2019.00080 
Kane, I. A., Clare, M. A., Miramontes, E., Wogelius, R., Rothwell, J. J., Garreau, P., et al. (2020). Seafloor microplastic hotspots controlle by deep-sea circulation. Science 368, 1140-1145. doi: 10.1126/science.aba5899

Katija, K., Choy, C. A., Sherlock, R. E., Sherman, A. D., and Robison, B. H. (2017). From the surface to the seafloor: how giant larvaceans transport microplastics into the deep sea. Sci. Adv. 3:e1700715. doi: 10.1126/sciadv.1700715

Koelmans, A. A., Kooi, M., Lavender Law, K., and van Sebille, E. (2017). All is not lost: deriving a top-down mass budget of plastic at sea. Environ. Res. Lett. 12:114028. doi: 10.1088/1748-9326/aa9500

Kohler, K. E., and Gill, S. M. (2006). Coral point count with excel extensions (CPCe): a visual basic program for the determination of coral and substrate coverage using random point count methodology. Comput. Geosci. 32, 12591269. doi: 10.1016/j.cageo.2005.11.009

Kramer, M. (2005). " $\mathrm{R}^{2}$ statistics for mixed models," in Proceedings of the 17th Conference on Applied Statistics in Agriculture. doi: 10.4148/2475-7772.1142

La Beur, L., Henry, L.-A., Kazanidis, G., Hennige, S., McDonald, A., Shaver, M. P., et al. (2019). Baseline assessment of marine litter and microplastic ingestion by cold-water coral reef benthos at the east mingulay marine protected area (sea of the Hebrides, Western Scotland). Front. Mar. Sci. 6. doi: 10.3389/fmars.2019. 00080

Leathwick, J. R., Elith, J., and Hastie, T. (2006). Comparative performance of generalized additive models and multivariate adaptive regression splines for statistical modelling of species distributions. Ecol. Model. 199, 188-196. doi: 10.1016/j.ecolmodel.2006.05.022

Lee, J. W., Kwon, O. H., Kim, T. K., Cho, Y. K., Choi, K. Y., Chung, H. Y., et al. (2013). Platelet-rich plasma: quantitative assessment of growth factor levels and comparative analysis of activated and inactivated groups. Arch. Plast. Surg. 40, 530-535. doi: 10.5999/aps.2013.40.5.530

Liubartseva, S., Coppini, G., Lecci, R., and Clementi, E. (2018). "Stochastic Lagrangian modeling the plastic marine debris in the Mediterranean Sea," in Proceedings of the EGU General Assembly Conference Abstracts (Vienna), 6480.

Lo, H. K. A., and Chan, K. Y. K. (2018). Negative effects of microplastic exposure on growth and development of Crepidula onyx. Environ. Pollut. 233, 588-595. doi: 10.1016/j.envpol.2017.10.095

Lusher, A. L., Hernandez-Milian, G., Berrow, S., Rogan, E., and O'Connor, I. (2018). Incidence of marine debris in cetaceans stranded and bycaught in Ireland: recent findings and a review of historical knowledge. Environ. Pollut. 232, 467-476. doi: 10.1016/j.envpol.2017.09.070

Martinelli, M., Gomiero, A., Guicciardi, S., Frapiccini, E., Strafella, P., Angelini, S., et al. (2021). Preliminary results on the occurrence and anatomical distribution of microplastics in wild populations of Nephrops norvegicus from the Adriatic Sea. Environ. Pollut. 278:116872. doi: 10.1016/j.envpol.2021.116872

Melli, V., Angiolillo, M., Ronchi, F., Canese, S., Giovanardi, O., Querin, S., et al. (2016). The first assessment of marine debris in a site of community importance in the north-western Adriatic Sea (Mediterranean Sea). Mar. Pollut. Bull. 114, 821-830. doi: 10.1016/j.marpolbul.2016.11.012

Moore, C. J. (2008). Synthetic polymers in the marine environment: a rapidly increasing, long-term threat. Environ. Res. 108, 131-139. doi: 10.1016/j.envres. 2008.07.025

Murray, F., and Cowie, P. R. (2011). Plastic contamination in the decapod crustacean Nephrops norvegicus (Linnaeus, 1758). Mar. Pollut. Bullet. 62, 12071217. doi: 10.1016/j.marpolbul.2011.03.032

Oehlmann, J., Schulte-Oehlmann, U., Kloas, W., Jagnytsch, O., Lutz, I., Kusk, K. O., et al. (2009). A critical analysis of the biological impacts of plasticizers on wildlife. Philos. Trans. R. Soc. B Biol. Sci. 364, 2047-2062. doi: 10.1098/rstb. 2008.0242

Pante, E., and Simon-Bouhet, B. (2013). Marmap: a package for importing, plotting and analyzing bathymetric and topographic data in R. PLoS One. 8:e73051. doi: 10.1371 /journal.pone.0073051

Rubec, P. J., Kiltie, R., Leone, E., Flamm, R. O., McEachron, L., and Santi, C. (2016). Using delta-generalized additive models to predict spatial distributions and population abundance of juvenile pink shrimp in Tampa Bay, Florida. Mar. Coast. Fish. Dyn. Manag. Ecosyst. Sci. 8, 232-243. doi: 10.1080/19425120.2015. 1084408

Russo, T., Carpentieri, P., D’Andrea, L., De Angelis, P., Fiorentino, F., Franceschini, S., et al. (2019). Trends in effort and yield of trawl fisheries: a case study from the Mediterranean Sea. Front. Mar. Sci. 6:153. doi: 10.3389/fmars.2019. 00153

Russo, T., D’Andrea, L., Parisi, A., Cataudella, and S. (2014). VMSbase: an rpackage for vms and logbook data management and analysis in fisheries ecology. PLoS One. 9:e100195. doi: 10.1371/journal.pone.0100195

Russo, T., D’Andrea, L., Parisi, A., Martinelli, M., Belardinelli, A., Boccoli, F., et al. (2016). Assessing the fishing footprint using data integrated from different tracking devices: issues and opportunities. Ecol. Indic. 69, 818-827. doi: 10. 1016/j.ecolind.2016.04.043

Sbrana, M., Zupa, W., Ligas, A., Capezzuto, F., Archonita, C., Follesa, M. C., et al. (2019). Spatio temporal abundance pattern of deep-water rose shrimp, Parapenaeus longirostris, and Norway lobster, Nephrops norvegicus, in European Mediterranean waters. Sci. Mar. 83, 1-10.

Shim, W. J., and Thomposon, R. C. (2015). Microplastics in the Ocean. Arch. Environ. Contam. Toxicol. 69, 265-268. doi: 10.1007/s00244-0150216-x

Talsness, C. E., Andrade, A. J. M., Kuriyama, S. N., Taylor, J. A., and vom Saal, F. S. (2009). Components of plastic: experimental studies in animals and relevance for human health. Philos. Trans. R. Soc. B Biol. Sci. 364, 2079-2096. doi: 10.1098/ rstb.2008.0281

Thompson, R. C., Swan, S. H., Moore, C. J., and vom Saal, F. S. (2009). Our plastic age. Philos. Trans. R. Soc. B Biol. Sci. 364, 1973-1976. doi: 10.1098/rstb.2009. 0054

Ungfors, A., Bell, E., Johnson, M. L., Cowing, D., Dobson, N. C., Bublitz, R., et al. (2013). Nephrops fisheries in European waters. Adv. Mar. Biol. 64, 247-314. doi: 10.1016/B978-0-12-410466-2.00007-8

Van Cauwenberghe, L., Vanreusel, A., Mees, J., and Janssen, C. R. (2013). Microplastic pollution in deep-sea sediments. Environ. Pollut. 182, 495-499. doi: 10.1016/j.envpol.2013.08.013

Ward, J. E., Zhao, S., Holohan, B. A., Mladinich, K. M., Griffin, T. W., Wozniak, J., et al. (2019). Selective ingestion and egestion of plastic particles by the blue mussel (Mytilus edulis) and Eastern oyster (Crassostrea virginica): implications for using bivalves as bioindicators of microplastic pollution. Environ. Sci. Technol. 53, 8776-8784. doi: 10.1021/acs.est.9b0 2073

Wood, S. (2012). mgcv: Mixed GAM Computation Vehicle with GCV/AIC/REML Smoothness Estimation.

Woodall, L. C., Sanchez-Vidal, A., Canals, M., Paterson, G. L. J., Coppock, R., Sleight, V., et al. (2014). The deep sea is a major sink for microplastic debris. R. Soc. Open Sci. 1:140317. doi: 10.1098/rsos.14 0317

Wright, S. L., Thompson, R. C., and Galloway, T. S. (2013). The physical impacts of microplastics on marine organisms: a review. Environ. Pollut. 178, 483-492. doi: 10.1016/j.envpol.2013.02.031

Conflict of Interest: The authors declare that the research was conducted in the absence of any commercial or financial relationships that could be construed as a potential conflict of interest.

Copyright (c) 2021 Franceschini, Cau, D’Andrea, Follesa and Russo. This is an openaccess article distributed under the terms of the Creative Commons Attribution License (CC BY). The use, distribution or reproduction in other forums is permitted, provided the original author(s) and the copyright owner(s) are credited and that the original publication in this journal is cited, in accordance with accepted academic practice. No use, distribution or reproduction is permitted which does not comply with these terms. 